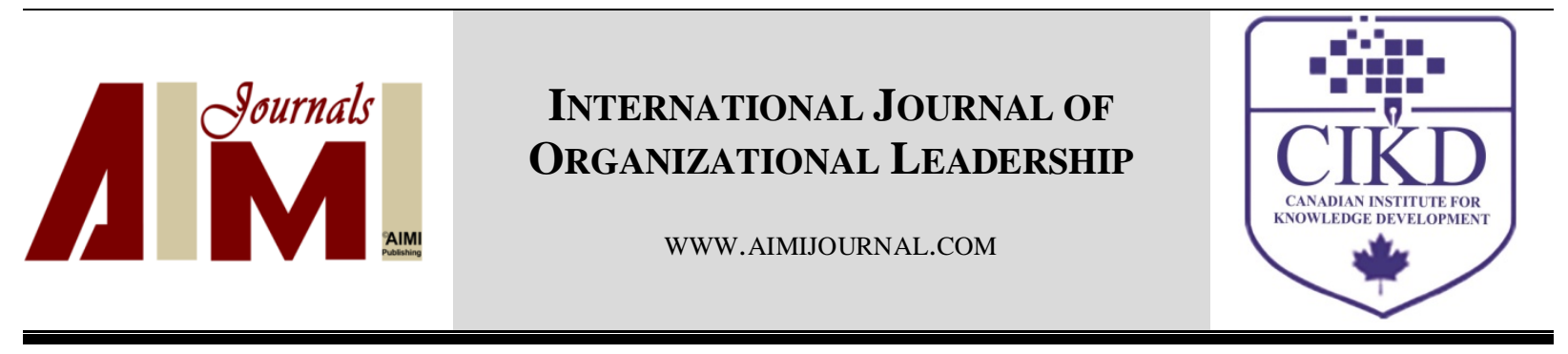

\title{
Leadership 4.0: Digital Leaders in the Age of Industry 4.0
}

\author{
Birgit Oberer $^{1 *}$, Alptekin Erkollar ${ }^{2}$ \\ ${ }^{1}$ Sakarya University, Business School, Sakarya, Turkey \\ ${ }^{2}$ Sakarya University, Management Information Systems Department, Sakarya, Turkey
}

\begin{abstract}
Keywords:

Digital leader, Industry 4.0, Leadership

Industry 4.0 stands for 'fourth industrial revolution' and is a term referring to rapid transformations in the design, production, implementation, operation, and service of manufacturing systems, products, and components. To get the most out of Industry 4.0 technologies, organizations will have to heavily invest in building capabilities in the following dimensions: data and connectivity, analytics and intelligence, conversion to the

Received

17 June 2018 physical world, and human-machine interaction. In this study, the human dimension of industry 4.0 has priority, by analyzing behavioral leadership theories that focus on the study of the specific behaviors of a leader (the leader behavior is the predictor of his leadership influences and is the best determinant of his leadership success). A two dimensional 4.0 leadership style matrix was developed (x-axis: innovation/technology concern; y-axis: people concern). The results of this study revealed that the developed industry 4.0 leadership style might have the dimensions of first-year students, social, technological or digital, where the 4.0 digital leader forms the highest reachable level in the 4.0 leadership matrix.
\end{abstract}

(C)AIMI Journals

The first three industrial revolutions happened as a result of mechanization, electricity, and information technology. The introduction of the Internet of Things into the manufacturing environment is forming the fourth industrial revolution, offering new business models and affecting value creating processes in an organization. Smart products are uniquely identifiable, can be located at all times, and their history, current status, and alternative routes to achieving their target state are all known. Digital transformation refers to the changes related to the 
application of digital technologies in all the aspects of human society. This digital revolution causes increased flexibility in production, increased speed, a new dimension of mass production, advanced productivity levels, superior quality results, and new emerging business models. Industry 4.0 focuses on the following main principles: information transparency and networking (Machines, devices, and people can communicate and exchange with one another). Industry 4.0 affects all the business areas since companies need both virtual and physical structures that enable collaboration between machines, devices, and people, and rapid adaptation along the value chain.

\section{Literature Review}

\section{Leadership}

Leadership is a complex topic and can be studied in different ways requiring different definitions. In this study, we do not use manager and leader interchangeably. A manager is a person who has a formal title and authority. A leader is a person who may be a manager or not, but they can influence others. Being a leader holding a formal position or being a manager is not mandatory (Lussier \& Achua, 2013). For this study, leadership is 'the influencing process of leaders and followers to achieve organizational objectives through change.' Traditionally, there are five essential elements to define leadership (DeRue \& Ashford, 2010) including leaders - followers, influence, organizational objectives, people, and change, summarized in Table 1.

Table 1

Leadership Key Elements

\begin{tabular}{ll}
\hline Leaders + Followers & $\begin{array}{l}\text { A follower is a person who is influenced by a leader. Good followers do not always say 'yes.' Good ones } \\
\text { give input to the leaders and influence them. }\end{array}$ \\
Influencing is a process of a leader communicating ideas, gaining acceptance, and motivating followers to \\
support and implement the ideas through change. Effective leaders can influence others. \\
Erganizational objectives & $\begin{array}{l}\text { Effective leaders create a shared vision for them and their followers and lead them to think about } \\
\text { organizational objectives. } \\
\text { Leadership is about leading people. Effective leaders like working with people, guiding them, and having a } \\
\text { shared vision. } \\
\text { People }\end{array}$ \\
Shange & environments quickly.
\end{tabular}

DeRue and Ashford (2010) defined the following managerial leadership skills: The interpersonal skills (people) involves the ability to understand, communicate, and work well with individuals and groups through developing productive relationships. Technical skills (things) involve the ability to use methods and techniques to perform a task. Decision-making skills (conceptional ideas) are based on the ability to conceptualize situations and select alternatives to solve problems and take advantage of opportunities. Managerial roles categories include interpersonal roles, informational roles, and decisional ones. Managerial roles could be a figurehead, leader, liaison, monitor, disseminator, spokesperson, entrepreneur, disturbance handler, resource allocator, or negotiator (as summarized in Table 2). 
Table 2

Managerial Roles (Mintzberg, 1973; Stackman \& Devine, 2011; Wyld, 2009)

\begin{tabular}{|c|c|c|}
\hline Category & Role & Description \\
\hline \multirow{3}{*}{ interpersonal } & Figurehead & $\begin{array}{l}\text { The leader represents the organization or department in legal, social, ceremonial and } \\
\text { symbolic activities }\end{array}$ \\
\hline & Leader & $\begin{array}{l}\text { Performing management functions to operate the manager's organization unit effectively. } \\
\text { The leader role influences how the leader performs other roles }\end{array}$ \\
\hline & Liaison & $\begin{array}{l}\text { Interacting with people outside the organizational unit, networking to develop and maintain } \\
\text { relationships that lead to power and influence }\end{array}$ \\
\hline \multirow{3}{*}{ Informational } & Monitor & Gathering information \\
\hline & Disseminator & Sending information to others within the organizational unit, managing knowledge \\
\hline & Spokesperson & Sending information to others outside of the organizational unit \\
\hline \multirow{3}{*}{ Decisional } & $\begin{array}{l}\text { Entrepreneur } \\
\text { Disturbance handler }\end{array}$ & $\begin{array}{l}\text { Innovate and initiate improvements } \\
\text { Corrective actions during conflict situations }\end{array}$ \\
\hline & Resource allocator & Scheduling, request authorization and perform budgeting activities \\
\hline & Negotiator & Representing the organizational unit during routine and non-routine transactions \\
\hline
\end{tabular}

Leadership theory is an explanation of some aspects of leadership. Theories have practical value because they help to understand, predict, and control successful leadership. The individual level, which focuses on the individual leader and their relationship with the individual followers; the group level, which focuses on the relationship between the leader and the collective group of followers; and the organizational level, focusing on organizational processes need to be considered for analyzing a leadership theory. There are different leadership theories to be distinguished, which are leadership trait theories (they attempt to explain distinctive characteristics accounting for leadership effectiveness), behavioral leadership theories (they attempt to explain the distinctive styles used by effective leaders), and contingency leadership theories, which attempt to explain the appropriate leadership style based on the leader, followers, and situation. Traits are distinguishing personal characteristics. Personality is a combination of traits that classifies an individual's behavior. Personality profiles identify individual stronger and weaker traits. Leadership style is a combination of traits, skills, and behaviors that leaders use as they interact with followers (Judge, Ilies, Bono, \& Gerhardt, 2002).

Lussier and Achua (2013) summarized the behavioral leadership theories as University of Iowa Leadership Styles (Lewin), University of Michigan Leadership Styles (Likert), and Ohio State University Leadership Styles (Stogdill). Lewin distinguishes the autocratic leadership style, where the leader makes the decision and tells the employees what they have to do, and the democratic leadership style, where the leader encourages participation in decisions and works actively with the employees. Likert distinguishes between the job centered leadership style and the employee-centered leadership style. The job centered leadership style measures goals and emphasizes work facilitation; and the leader directs subordinates with clear roles and goals, and the managers tell them what they have to do to achieve the goals. The employeecentered leadership style measures supportive leadership and interaction facilitation. The leader focuses on meeting the human needs of the employees while developing relationships. Stogdill focuses on initiating structure and consideration and develops four leadership styles including LOW Structure/HIGH Consideration, HIGH Structure/HIGH Consideration, LOW 
Structure/LOW Consideration, and HIGH Structure/LOW Consideration. Leaders with high structure and low consideration use one-way communication; the managers make decisions.

Leaders with high consideration and low structure use two-way communication; they share the decision making. To point out the differences between the models; the Michigan and Iowa leadership styles are one-dimensional with two leadership behaviors at opposite ends and two leadership styles; whereas the Ohio State leadership styles are two-dimensional with two behaviors independent of one another and four leadership styles.

The Leadership Grid Theory (Blake \& Mouton, 1964), which is based on Ohio and Michigan studies, defines two dimensions: (1) concern for the production and (2) concern for people, is measured through a questionnaire on a scale from 1 to 9 , has 81 possible combinations of concern for production and people, and identifies five leadership styles:

- $\quad 1.1$ impoverished: The impoverished leader $(1,1)$ has low concern for both production and people. The leader does the minimum required to remain employed in the position.

- 9.1 authority compliance: The authority-compliance leader (9.1) has a high concern for production and a low concern for people. The leader focuses on getting the job done while people are treated like machines.

- 1.9 country club: The country-club leader (1.9) has a high concern for people and a low concern for production. The leader strives to maintain a friendly atmosphere without regard for production.

- 5.5 middle of the road: The middle-of-the-road leader (5.5) has balanced, medium concern for both production and people. The leader strives to maintain satisfactory performance and morale.

- $\quad 9.9$ team leader: The team leader (9.9) has a high concern for both production and people. This leader strives for maximum performance and employees' satisfaction. The team leadership style is generally the most appropriate to use in all situations (Lussier \& Achua, 2013).

\section{Industry 4.0}

Industry 4.0 stands for 'fourth industrial revolution' and is a term referring to rapid transformations in the design, production, implementation, operation, and service of manufacturing systems, products, and components. Industry 4.0, a German government initiative that promotes the automation of the manufacturing industry to develop smart factories, is a disruptive paradigm, challenging the ways manufacturers think about knowledgeintensive industrial processes, making manufacturing more flexible, smarter, and more effective. If a man, machine, and processes are arranged in intelligent, smart networks, highquality products might be created more rapidly, and competitive advantages by making production costs more competitive might be created (Bauernhansl, Ten Hompel, \& VogelHeuser, 2014; Bienzeisler, Schletz, \& Gahle, 2014; Henke, 2014).

Industry 4.0 depends on a number of innovative technological developments such as information and communication technologies (ICT), which are used to digitize information and integrate systems at all stages of product development and service life, both inside an organization and in a cross-organizational way in order to monitor and control the physical processes and systems as well as support human workers by using robots, intelligent tools, and 
augmented reality (Davis, 2015; Fraunhofer, 2013). Industry 4.0 digitizes and integrates processes vertically across the entire organization, from product development and purchasing, through manufacturing, logistics, and service (Bauernhansl et al., 2014). Smart factories allow individual customer requirements.

\section{The Study: Creating the '4.0 Leadership Matrix for Digital Leaders'}

This study examines behavioral leadership styles to draw a picture of how a leader should be at the age of Industry 4.0 and develop a 4.0 leadership style matrix. In this study an inductive research approach is followed, with a descriptive research design, applying a qualitative research methodology and document analysis as a main research method. In Industry 4.0, dynamic business and engineering processes enable last-minute changes to production and which results in new ways of creating value and new innovative business models. Industry 4.0 has an impact on all business areas. To successfully implement Industry 4.0, according to Kagerman et al. (2013), the following areas have to be considered:

- $\quad$ Standardization (1)

- Managing complex systems (2)

- Comprehensive communication structure (3)

- $\quad$ Safety and security (4)

- $\quad$ Resource efficiency (5)

- Regulatory framework (6)

- Work organization and design (7)

- $\quad$ Training and continuous professional development (8)

This study focuses on (7), the human resource perspective of Industry 4.0: the role of employees is changed under industry 4.0. Increased real-time oriented control structures need to be implemented, which leads to a transformation in work content, processes, and the whole work infrastructure and environment. Workers will have the opportunity to take on more responsibility in their work sphere and thus personal development will be enhanced. To make these developments possible, operative management routines and even more important leadership styles (Ganschar et al., 2013; Koch, Kuge, Geissbauer, \& Schrauf, 2014; Zuehlke, 2010) should be adopted.

\subsection{Leaders - Digital Leaders at the Age of Industry 4.0}

Why is there a need for an Industry 4.0 related leadership style? Digitalization leads to a transformation of production, logistics, communication, and human resource management. Innovative approaches need to create value from digitalization, connected smart devices, and establish new ways of communication and collaboration. Industry 4.0 is about competitiveness and innovation. Organizations need to adapt their capabilities to handle new challenges. Besides change management, which is a sequential concept, design thinking is an iterative approach linking creative and analytical methods. The goal is to foster the development of new ideas and concepts and increase the innovative power as well as the competitiveness of organizations. A significant challenge for Industry 4.0 is not only to find or implement the right technology, it is also a lack of digital culture and skills in the organization. Industrial 
companies need to develop a robust digital culture and to ensure that clear leadership drives the change.

There is a need for developing a leadership 4.0 culture in organizations. That is why, in this study, '4.0 leadership style matrix' was designed, which is a behavioral style. Digital technologies have an influence not only on the area of information technology but also on how businesses are managed and what kind of leadership styles are applied. Leadership 4.0 stands for leadership in the age of industry 4.0. These 4.0 leaders are called digital leaders. Not every leader in a tech company is a digital leader. Germany as the showcase country, where industry 4.0 originates, is prosperous regarding industry 4.0 and Internet of Things. However, doesn't this mean that the managers of these (German) companies are automatically digital leaders? What makes a leader a digital one is not the area the company is working in. It is a question of leadership style and the abilities of these leaders to inspire their employees to innovate and hold onto their ideas.

Essential elements determining digital leaders are organizational objectives (the ability to move from fixed cycles for assessing employee performance, up to the ability to understand that situations determine the need for assessing employees and teams equally, with the ability to implement feedback routines), people ( the ability to distribute tasks based on the situation and team competence, linking the abilities of managers and employees to form a competence networking intelligence), change (high level willingness and ability for change, encouraging high level agility between the market, customer, partners, and employees, and deliberating promotion), output (the ability to control processes, evaluate tasks and results together with teams; to use resources according to competence - cross-hierarchical and cross functional instead of controlling orders, resource plans, and evaluating results within the borders of a project, like traditional leaders do), mistakes and conflicts (creating an open atmosphere with the learning effect in errors and a collaborative atmosphere for handling conflict situations), communication (the ability to create a transparent framework for information distribution, counting on employees' and teams' collectable debt of self-responsibility, and proactive behavior) as well as innovation (knowing that innovation is learnable, being able to transform old structures through the use of multidisciplinary teams, and creative processes and flexible work environments).

\section{Definition of the '4.0 Leadership Style for Digital Leaders'}

Digital leadership (leadership 4.0) is a fast, cross-hierarchical, team-oriented, and cooperative approach, with a strong focus on innovation. The personal competence of the leader, their mindset as well as their ability to apply new methods and instruments such as design thinking, are critical dimensions for 4.0 leaders. Design Thinking is a methodology used by designers to solve complex problems and find desirable solutions. A design mindset is a solution focused and action-oriented toward creating a preferred future. In business management, it could be used as a step-by-step process to find and execute solutions that improve profits, efficiency, and customer satisfaction; and to keep business ahead of the innovation curve. Industry 4.0 requires companies to think in new ways. 


\section{Categorizing the '4.0 Leadership Style for Digital Leaders' in the Behavioral Leadership Theories}

Considering the University of Iowa Leadership Styles, the " 4.0 leadership style for digital leaders' would be comparable to the democratic style. In democratic leadership style, the leader encourages participation in decisions and works actively with the employees. In 4.0 leadership style, the leader encourages active participation in creative working and encourages employees and teams to work decentralized, with the less active participation of the leader. Employees and teams should work actively, independently, creative and innovative with less leader involvement.

Considering the University of Michigan Leadership Styles, the ' 4.0 leadership style for digital leaders' would be comparable to the employee-centered style. Employee centered leadership style measures supportive leadership and interaction facilitation. 4.0 leadership style focuses on innovation and people. Employees in the center of focus, by developing their creative capabilities, guide them to work in creative teams to provide the organization with innovative solutions.

Considering the Ohio State Leadership Styles, the '4.0 leadership style for digital leaders' would be comparable to the LOW Structure/HIGH Consideration style. In LOW Structure/HIGH Consideration style, leaders with high consideration and low structure use two-way communication and the share of decision making. 4.0 leadership style focuses on low structure and high consideration. Structure is not much important for the 4.0 leader. They focus on consideration. Differently, to the Ohio State style, which focuses on decision making, the 4.0 leadership style focuses on consideration concerning innovation.

Considering the Leadership Grid Theory, the '4.0 leadership style for digital leaders' would be comparable to style \# 5 (9/9). Blacke’s style 5: ‘team leader’ (9/9), involves with high concern for production and people. 4.0 leadership style involves with high concern for innovation and people. Team oriented focuses on innovation and people.

\section{The '4.0 Leadership Style Matrix'}

A two dimensional 4.0 leadership matrix was developed (x-axis: innovation/technology concern; y-axis: people concern). This matrix should help to choose the most appropriate 4.0 leadership style, based on the degree of innovation and technology orientation and the people leading. The matrix is divided into four quadrants. Each quadrant lists one leadership style that is best suited for a specific person. The X-axis describes the individual's capability and focuses on technology and innovation orientation. Several factors influence how technology/innovation oriented an individual is such as education, expertise, skills, and motivation. The Y-axis defines the 'people concern' of the person. Several factors influence how people-oriented an individual is such as education, skills, and the desire for interaction and communication. For instance, a person with a high level of education in a technology related field is likely to want a technology-oriented leadership style such as TL (4.0 technology leader) or DL (4.0 digital leader, if they also have a high employee orientation). A person that is generally seeking employee commitment to decisions tends to prefer an employee-focused leadership style such as EL (4.0 social leader). Someone with no specific orientation, neither toward people's 
concerns nor to technology/innovation concerns, has a low/low situation, with low person concern as well as low technology/innovation concern.

FL (4.0 Freshmen Leader) is concerned with an ability to focus on traditional manufacturing structures with the primary focus on the finalized product; it has no employee focus, customer needs of minor interest, same for emerging technologies. SL (4.0 Social Leader) refers to an ability to create a friendly atmosphere for employees without regard to innovation and technology. Supporting employees is important. TL (4.0 Technological Leader) is related to an ability to determine how new technology can be used to deliver enhanced value; it has a strong focus on innovation and a low employee focus. DL (4.0 Digital Leader) focuses on ability to understand how technology impacts people and the organizational model is aligned with human nature. These are equally essential elements of digital leadership. The '4.0 Digital Leader' leadership style is the most productive 4.0 leadership style. Figure 1 shows the ' 4.0 leadership matrix' developed in this study.

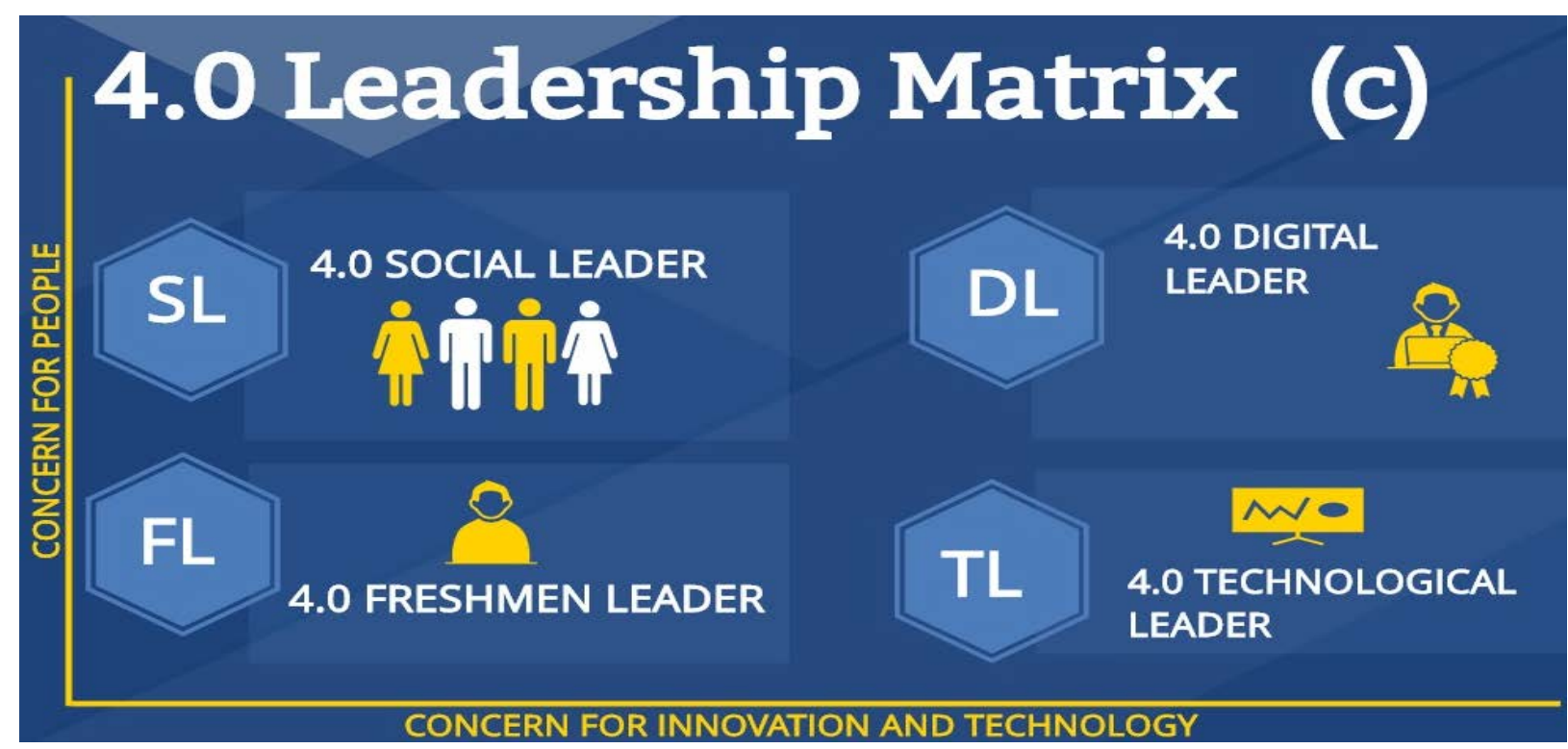

Figure 1. Leadership matrix

\section{Conclusions and Recommendations}

The journey toward Industry 4.0 is an evolutionary process, where technologies have to be adapted to the emerging requirements of manufacturing and innovation management; new business models have to be developed for new markets, new locations, new products, and services as well as new forms of cooperation and collaboration. There is no one best leadership style in all situations. There has to be consent in a style where employees are more satisfied with leaders. With behavioral leadership research, there is a shift with more focus on the human side of the organization to increase the productivity and efficiency of the whole value chain. Leadership 4.0 stands for leadership in the age of industry 4.0. The 4.0 Leadership Style for Digital Leaders is a fast, cross-hierarchical, team-oriented, and cooperative approach, with a strong focus on innovation. In a follow-up study, the leadership matrix developed in this study should be applied and the leaders' way along the 4.0 leadership matrix should be further analyzed. Strategies should be defined by guiding a leader to move forward along the matrix up 
to the most productive 4.0 leadership style, which is the ' 4.0 digital leader'. Furthermore, it should be analyzed as to whether the x-axis should remain as 'technology and innovation' or if these two domains should be separated, since there might be leaders focusing on technology but not on innovation and vice versa.

\section{References}

Bauernhansl, T., Ten Hompel, M., \& Vogel-Heuser, B. (Eds.). (2014). Industry 4.0 in Produktion, Automatisierung und Logistik- Anwendung, Technologien, Migration [Industry 4.0 in production, automation and logistics application, technologies, migration] (pp. 1-648). Wiesbaden: Springer Vieweg.

Blake, R. R., \& Mouton, J. S. (1964). The managerial grid. Houston: Gulf Publishing Company.

Bienzeisler, B., Schletz, A., \& Gahle, A. K. (2014). Industry 4.0 ready services technologie trends 2020. Stuttgart: Fraunhofer IAO.

Davis, R. (2015). Industry 4.0. Digitalization for productivity and growth. European Parliamentary Research Service, PE 568.337. Retrieved from http://www.europarl.europa.eu/RegData/etudes/BRIE/2015/568337/EPRS_BRI (2015)568337_EN.pdf.

DeRue, D., \& Ashford, S. (2010). Who will lead and who will follow? Social process of leadership identity construction in organizations. Academy of Management Review, 35(4), 627-647.

Fraunhofer IOSP. (2013). Industry 4.0 - information technology is the key element in the factory of the future. Fraunhofer Institute of Optronics, System Technologies and Image Exploitation, PR, 31.01.2013, pp.1-5.

Ganschar, O., Gerlach, S., Hämmerle, M., Krause, T., Schlund, S., \& Spath, D. (2013). Produktionsarbeit der zukunft Industry 4.0 [Production work of the future - Industry 4.0]. Fraunhofer IAO.

Henke, M. (2014). Management der Industry 4.0 - Herausforderungen und Handlungsfelder für die erfolgsorientierte Steuerung von Unternehmen [Management of Industry 4.0 - Challenges and Fields of Action for the Success-oriented Management of Companies]. Presentation at Zukunftskongress Logistik 32. Dortmunder Gespräche, p. 5.

Judge, T., Ilies, R., Bono, J., \& Gerhardt, M. (2002). Personality and leadership: A qualitative and quantitative review. Journal of Applied Psychology, 87(4), 765-768.

Koch, V., Kuge, S. Geissbauer, R., \& Schrauf, S. (2014). Industry 4.0. Opportunities and challenges of the industrial internet. Munich: Strategy and PwC.

Lussier, R., \& Achua. C. (2013). Leadership. Theory, application and skill development. Soth-Western: Cengage Learning.

Mintzberg, H. (1973). The nature of managerial work. New York: Harper and Row.

Stackman, R., \& Devine, K. (2011). Leadership and emotional - rational coherence: A start? Academy of Management Perspectives, 25(1), 42-44.

Wyld, D. (2009). What matters more in growth companies: leader or idea? Academy of Management Perspectives, 23(2), 9596.

Zuehlke, D. (2010). Smart factory - Towards a factory-of things. Annual Reviews in Control, 34, 129-138. 